\title{
Evaluation of dog spaying, animal welfare, and dog owner/caretaker knowledge in Afyonkarahisar Province ${ }^{1)}$
}

\author{
DUYGU BAKI ACAR \\ Department of Obstetrics and Gynaecology, Faculty of Veterinary Medicine, \\ Afyon Kocatepe University, TR-03200, Afyonkarahisar, Turkey
}

\section{Baki Acar D. \\ Evaluation of dog spaying, animal welfare, and dog owner/caretaker knowledge in Afyonkarahisar Province \\ Summary}

The present study evaluated the demographics and knowledge of the dog owners regarding the importance of dog spaying/neutering and animal welfare in Afyonkarahisar Province. Therefore, the original questionnaires were prepared to evaluate the knowledge of dog owners/caretakers about dog reproduction, spaying of dogs, and stray animal welfare. The mean age of participants was 33 , and $51.8 \%$ of responders were female and $48.2 \%$ were male. Most of the dogs $(83.7 \%)$ were not spayed/neutered and spaying/neutering age was $\geq 2$ years. Fifty-five per cent of owners had a dog for more than 5 years, and only $2 \%$ of dogs were obtained from a dog shelter. Most of the participants reported that municipalities should take more active roles and increase the number and quality of animal shelters. Adopting dogs from shelters, putting food and water containers on the streets for stray dogs, and promoting the awareness of people regarding animal rights and welfare were among the responses. There was a knowledge deficiency regarding the importance of spaying/neutering dogs, especially spaying females, and the reproductive characteristics of dogs that may cause an increase in the stray dog population and unwanted puppies. The results of this study revealed that the dissemination of accurate information to people is a crucial point in the welfare of both stray and owned dogs and controlling the overpopulation of free-roaming dogs.

Keywords: spaying, owner knowledge, stray dog, animal welfare

There are many studies about companion animal ownership, and the most commonly owned pet species are cats and dogs $(3,5,11,24,37)$. Dogs are also called 'man's best friend' and regarded as the ideal model of animal companionship (37). Nonetheless, being an owner of a dog is a big responsibility. Millions of dogs are abandoned by the owners or are released to animal shelters due to unwanted litter, behavioral problems such as aggression toward people or other animals, lack of time for the dog, allergies, etc. (31, 34, 36). According to Alexander et al. (2), unwanted litter is the primary reason for relinquishment of dogs. Some owners keep their dogs outdoors, and if these dogs are free-ranging or unneutered, they mate freely. In these circumstances, there is a growing number of unplanned and/or unwanted litters (13).

The estrus cycle of canines is described as monoestrous. Bitches are non-seasonal, polytocous, sponta-

This research had been funded by Scientific Research Projects Coordination Unit of Afyon Kocatepe University (Project Code: 16.KARIYER.136). neous ovulators, and have a spontaneous luteal phase similar in length to pregnancy followed by an obligate anestrus before the next 2-3 week heat period (proestrus and estrus (6). The first proestral bleeding or heat in bitches is called puberty, and the average age of the first estrus is 6-0 months (varying from 4 months to 2 years). Puberty depends on the breed size: small breed bitches cycle earlier in life than large and giant breed bitches $(6,29)$. The estrous cycle of the domestic bitch has a different timing of the cycle stages and consists of four stages proestrus, estrus, diestrus (metestrus) and anestrus. Proestrus is the first stage of the estrous cycle, in which the bitch exhibits external signs, such as turgid swelling of the vulva, serosanguinous vulvar discharge, and behavioral changes. This stage lasts an average of 9 days and ranges from 0 to 22 days. The estrus stage occurs shortly after an estradiol surge, and behavioral changes begin: the bitch allows the male to mount and breed her. Vulvar softening and change in the color of vulvar discharge to straw-colored 
are remarkable signs. The estrus stage lasts a variable length of time from 3 to 21 days (mean 9 days). Both pregnant and non-pregnant bitches are considered to be in diestrus (metestrus), and the pregnancy status does not alter the length of diestrus; this stage lasts about 2 months. Anestrus is called a reproductive quiescence period, and in this stage, there are no specific physical or behavioral changes. The anestrus stage lasts about 4-5 months, but may vary widely, and then a new proestrus begins, following anestrus $(12,29,32)$.

In veterinary sciences, the number of offspring is an important trait, especially in livestock production and pet breeding. Depending on the amount of the litter per birth, mammalian species can be described as either monotocous or polytocous, and dogs are a polytocous species (1). In bitches, the litter size varies between 1 and 13 (rarely much more than 13 puppies), and smaller breeds tend to have smaller litters ( $\leq 4$ puppies) than larger breeds ( $\geq 7$ puppies) (16, $20,19)$. In valuable breeding dogs, a large litter size is an advantage. However, especially in free-roaming and stray dogs, a large litter size creates a significant risk for animal welfare and pet population control programs, and unplanned pregnancies also lead to abandoned pups. Therefore, ovariectomy or ovariohysterectomy are most often performed in bitches to control pet population or prevent unwanted litters all over the world $(14,15,30)$. Ovariohysterectomy is preferred over ovariectomy because some pathological conditions, such as pyometra and reproductive tract neoplasms, can be treated by this operation $(7,8)$. In Turkey, municipalities are progressing well on "neuter and vaccinate stray animal" programs, and there are several non-governmental organizations cooperating with governmental agencies to prevent uncontrolled reproduction of stray animals (23).

There is very little published data about the importance of owned/stray dog spaying/neutering, dog owners' views on the spaying/neutering of dogs, and stray dog welfare in Turkey. For this reason, we aimed 1) to evaluate the knowledge of dog owners living in Afyonkarahisar about the importance of dog spaying/ neutering, and to determine whether they had spayed/ neutered their dogs or not; as well as 2) to inform the dog owners about stray animal welfare and protection strategies in the present study.

\section{Material and methods}

We conducted a survey regarding dog welfare and reproduction in Afyonkarahisar Province. During the study, we collected answers from participants to questions prepared according to the goals of the province. Thus, the original questionnaire was prepared to evaluate the knowledge of dog owners/caretakers regarding dog reproduction, as well as their thoughts on spaying dogs and stray animal welfare. The questions were asked as a series of multiple-choice and open-ended questions. The questionnaire consisted of three sections: 1) Demographic information about owners/care- takers, including gender, age, household composition, level of education, income level, and marital status; 2) Information about the experience of dog owners with pet animal ownership and care; 3) General information about the dogs owned, including reproductive status of dogs, neutering, breeding, health status, and knowledge of dog reproduction and stray/free-roaming dog welfare. The data were analyzed by frequency analysis using the statistical program SPSS 20.0 for Windows (SPSS Inc., Chicago, IL, USA).

\section{Results and discussion}

In this study, a total of 182 questionnaires were given to participants to complete, and $112(61.5 \%)$ questionnaires were returned partially or fully completed. The number of responses analyzed varied for each question because not all the forms were fully completed.

The results of the demographic information are summarized in Table 1. The mean age of participants

Tab. 1. Demographic information about dog owners/caretakers $(\%)$

\begin{tabular}{|l|c|}
\hline \multicolumn{1}{|c|}{ Characteristics } & $\%$ \\
\hline Gender & \\
\hline Male & 48.2 \\
\hline Female & 51.8 \\
\hline Level of education & \\
\hline Primary school & 6.5 \\
\hline Secondary school & 1.2 \\
\hline High school & 10.4 \\
\hline University & 67.2 \\
\hline Master's degree/Doctoral degree & 14.7 \\
\hline Living area & \\
\hline City center & 72.6 \\
\hline Town & 11.3 \\
\hline Village & 16.1 \\
\hline House type & \\
\hline Flat & 56.4 \\
\hline House with a garden & 43.6 \\
\hline Income level & \\
\hline < 500,00 TL & 11.6 \\
\hline $500,00-999,00$ TL & 12.3 \\
\hline 1.000,00-1.999,00 TL & 19.3 \\
\hline 2.000,00-3.999,00 TL & 19.3 \\
\hline Household composition & 19.3 \\
\hline 1 Person & 29.8 \\
\hline 2 Persons & \\
\hline S Persons & \\
\hline Dingle & \\
\hline
\end{tabular}


Tab. 2. Information about the experience of dog owners with pet animal ownership and care (\%)

\begin{tabular}{|l|r|}
\hline \multicolumn{1}{|c|}{ Experience characteristics } & $\%$ \\
\hline Number of dog & \\
\hline 1 & 70.7 \\
\hline 3 & 10.5 \\
\hline 4 & 8.2 \\
\hline$\geq 5$ & 4.2 \\
\hline Owned pets & 6.4 \\
\hline Cat and dog & \\
\hline Only dog & 31.4 \\
\hline Owned dog sex & 68.6 \\
\hline Male & \\
\hline Female & 34.0 \\
\hline Both male and female & 44.0 \\
\hline Ownership experience & 22.0 \\
\hline$<1$ year & \\
\hline 1-3 years & 13.7 \\
\hline 3-5 years & 17.6 \\
\hline$\geq 5$ years & 13.7 \\
\hline Source & 55.0 \\
\hline Strayed in & 27.4 \\
\hline Animal shelter & 2.0 \\
\hline Friend/relatives & 53.0 \\
\hline Owned dogs puppy & 2.0 \\
\hline Pet shop & 7.8 \\
\hline Multiple choice & \\
\hline Housing & \\
\hline Always indoor & \\
\hline Always outdoor & \\
\hline Indoor but access to outside anytime & \\
\hline
\end{tabular}

was 33 (range 17-58 years); $51.8 \%$ of responders were female and $48.2 \%$ were male; and education was mostly at the university level (67.2\%). In the second section, experiences of dog owners/caretakers were evaluated, and these data are shown in Table 2. Seventy percent of owners/caretakers had only one dog, and the remaining owners had 2 or more dogs. Most (68.6\%) had only a dog and no other animal species. Fifty-five percent of owners had a dog for more than 5 years, while only $2 \%$ owned a dog from a shelter. Overall, $53.0 \%$ of owners stated that the dogs were kept outdoor year-round, 29.4\% were housed indoors but with independent access to the outside, and $17.6 \%$ were housed indoors exclusively. In the third section, information regarding the dogs owned (Tab. 3), knowledge about dog reproduction, and stray/free-roaming dog welfare were evaluated. Most of the dogs $(83.7 \%)$ were not spayed/neutered, and the spaying/neutering age was $\geq 2$ years. When owner knowledge concerning dog reproduction was analyzed, $63.6 \%$ of participants
Tab. 3. The information about owned dogs and owner knowledge $(\%)$

\begin{tabular}{|c|c|}
\hline Owned dog characteristics & $\%$ \\
\hline \multicolumn{2}{|l|}{ Age of puberty } \\
\hline$<6$ months & 10.6 \\
\hline 6-12 months & 68.1 \\
\hline $12-18$ months & 17.0 \\
\hline$>18$ months & 4.3 \\
\hline \multicolumn{2}{|l|}{ Spayed/neutered } \\
\hline Yes & 16.3 \\
\hline No & 83.7 \\
\hline \multicolumn{2}{|c|}{ Allow dog to go out during heat cycle } \\
\hline Yes & 40.4 \\
\hline No & 59.6 \\
\hline \multicolumn{2}{|l|}{ Unwanted puppies } \\
\hline Yes & 13.7 \\
\hline No & 86.3 \\
\hline \multicolumn{2}{|c|}{ Owner knowledge } \\
\hline \multicolumn{2}{|c|}{ Should dogs be whelped before spaying? } \\
\hline Yes & 62.7 \\
\hline No & 23.7 \\
\hline I don’t know & 13.5 \\
\hline \multicolumn{2}{|l|}{ First mating age of dogs } \\
\hline $0-5$ months & 1.8 \\
\hline 6-1 months & 18.2 \\
\hline $12-18$ months & 63.6 \\
\hline$>18$ months & 16.4 \\
\hline \multicolumn{2}{|l|}{ Can relative dogs mate? } \\
\hline Yes & 60.0 \\
\hline No & 19.0 \\
\hline I don't know & 21.0 \\
\hline
\end{tabular}

answered that the first mating age of dogs was between $12-18$ months, $60.0 \%$ responded that related dogs could be mated, and $86.3 \%$ of the owners reported that they had no unwanted puppies.

One of the main goals of this study was to determine the perspective of dog owners/caretakers regarding stray/free-roaming dogs, including what could be done to improve their welfare status. Two open-ended questions were asked about this issue, and a common idea was that they should be neutered, vaccinated, and placed in a shelter. Most of the participants reported that municipalities should take a more active role and increase the number and quality of animal shelters. Adopting dogs from shelters, putting food and water containers on the streets for stray dogs, and promoting awareness of people to animal rights and welfare were among the answers. Only a few participants $(3.2 \%)$ reported that killing/euthanizing stray dogs was an option to decrease the number of stray dogs.

Survey studies have some limitations, such as study design, obtaining accurate results, generalizability, 
inadequate sampling, and low survey return rates (28). The response rate is one of the critical issues in a survey study, and it may affect the validity and credibility of the results. Thus, higher response rates ensure a more reliable survey study (4). There are many reasons for not responding to questionnaires; people are too busy, do not consider the topic relevant, don't have the address to return the questionnaire, and company policy may mandate no completion of surveys. Some scholars have indicated that the minimal response rate should be 50 to 60 percent $(4,9)$. In the present study, the response rate increased the validity of our study. The response rate of this study was $61.5 \%$, which was favorable compared to many recent survey studies (4, $28,33)$.

The demographic data for dog owners was obtained in the present study. The gender of dog owners was similar, the mean age of respondents was 33 years, most had a household composition of $\geq 4$ people, and the majority of participants had a higher level of education. Compared to male respondents, female respondents were more keen regarding owning a dog (25). In contrast, more studies have reported that no gender effect was found for dog ownership similar to our result $(4,19,31)$. Household size may affect being a dog owner because as the number of people increased, the likelihood of dog ownership increased (35). The present study confirmed this finding because of the composition of households. In addition, there were so many university students in the province, and they were more likely to own a pet if they lived in a student house. Dog owners usually preferred to have a detached house to use its garden for the dog's exercise and training activities, and mostly live in semi-urban or rural locations $(11,24)$. In contrast, the rate of participants living in the urban areas was higher than those living in the semi-urban or rural areas, and the apartment housing was slightly higher than that of houses with gardens in the present study. In the Afyonkarahisar City center, apartments are more preferable to a detached house, and the great majority of the population live in apartments. Thus, the difference between our results and the general view regarding dog ownership and the household type might be caused by the layout of the city.

Murray et al. (24) reported that pet owners choose mostly one species of pet, such as only a dog or cat, because of the possibility of inter-species aggression. The majority of dog owners had only one dog. Our results were in accordance with those of Murray et al. (24) who found that most of the dog owners $(68.6 \%)$ had only dogs and no other pet species. Additionally, the rate of single dog ownership was $70.7 \%$. However, our results differed from those of Fielding et al. (14) in that they reported the mean number of dogs owned as 2.4 .

Although the rate of obtaining dogs from the animal shelter was low $(2 \%)$, the adoption rate for stray dogs was $27.4 \%$. The remainder of dog owners obtained their dogs from a familiar person, pet shop, or owned the dog's mother. Relinquishment of pet dogs to shelters is an important problem for animals because these dogs are exposed to various contagious diseases, psychological stressors, isolation, disruption of familiar routines, and loss of control over environmental contingencies (34). Adopting pets from shelters is a salvation for them but adoption in not a guarantee of lifelong security, as dogs may be returned to shelters because of the dissatisfaction of the new owner (22). For this reason, animal shelters may be the first option for obtaining a dog. Thus, adopters should support unwanted dog welfare and also contribute to decreasing the overcapacity of shelters.

A high proportion (53.0\%) of owners kept their dog outdoor year-round, and only $16.3 \%$ of dogs were spayed or neutered. Additionally, the age of spaying or neutering was $\geq 2$ years in the present study. In Turkey and the rest of the world, overpopulation of stray dogs is a huge problem. Animal-welfare agencies often offer programs promoting surgical spaying or neutering to reduce the number of unwanted dogs (34). In Italy, the owned dog population increases $2.6 \%$ annually, and the spaying/neutering rate of owned dogs is estimated at $30 \%$ (9). Our spaying/neutering results was lower than that of Italy and owners kept their dogs outdoors. The reason for the lower rate may reflect poor owner knowledge about the close relationship between the size of the total breeding population and the stray population. Thus, it is suggested that one of the most critical issues is informing pet owners of the stray population problem. The majority of dog owners $(62.7 \%)$ answered yes to "dogs should be whelped before spaying" question, and most of them $(63.6 \%)$ believed that "first mating age of dogs" was 12-18 months in the present study. Puberty and the first fertile mating age of dogs vary between 6 to 14 months in most breeds (6). Where we can understand that the knowledge of owners about the first mating age and whelping before spaying may cause unwanted puppies and increase in the stray dog population. Therefore, the importance of accurate information is illustrated again.

Free-roaming animals pose a substantial problem for both public health and animal welfare, especially in developing countries and also for Turkey $(26,34)$. These animals face infectious diseases, venereal tumors, malnutrition, starvation, lovelessness, and high mortality. Furthermore, female dogs have shorter lifespans related to abandonment relative to those that avoid pregnancies, unwanted puppies, and estrus behaviors. Stray dogs are not only a problem for animal welfare but also a problem for humans because of zoonoses, such as rabies, echinococcosis, and toxocariasis (18). To solve the free-roaming animal issue, the World Health Organization (WHO) and the World Society for the Protection of Animals (WSPA) issued a guideline in 1992, including vaccination, identifica- 
tion, sales, breeding, public education, neutering, and early spaying (21). Over the past few decades, animal protection organizations defined new perspectives to prevent uncontrolled reproduction and to preserve animal rights in live capture, neuter, and release (CNR) programs for stray dogs. In this program, stray dog control can be managed, and dogs can return to their home territories. In this way, the "vacuum effect" of attracting new dogs to unoccupied territories can be avoided (18). In some countries, some animal adoption agencies spay/neuter all companion animals after adoption and promote prepubertal gonadectomy (17). In Turkey, the "Animal Protection Law" entered into force in 2004, and throughout the country, new goals to "terminate animal culling, establish care units for animals, neuter and vaccinate stray animals" have been put into the practice (23). In the Afyonkarahisar Province, the CNR program has been applied over a decade in collaboration with Afyonkarahisar Municipality and Afyon Kocatepe University, and through this program thousands of male and female stray dogs have been vaccinated, spayed/neutered, and returned to their territory.

In conclusion, demographics, experiences and knowledge levels regarding dog reproduction and stray/free-roaming dog welfare of dog owners/caretakers were established for Afyonkarahisar Province for the first time. A knowledge deficiency was revealed regarding the importance of spaying/neutering animals, especially spaying females, and the reproductive characteristics of dogs that may cause an increase of in the stray dog population and unwanted puppies. The results of this study revealed that providing people accurate information is a crucial point regarding the welfare of both stray and owned dogs and controlling the overpopulation of free-roaming animals.

\section{References}

1. Ahn H., Kim K. W., Kim H. J., Cho S., Kim H.: Differential evolution between monotocous and polytocous species. Asian Australas. J. Anim. Sci. 2014, 27, 464-470.

2. Alexander S. A., Shane S. M.: Characteristics of animal adopted from an animal control center whose owners complied with a spaying/neutering program. J. Am. Vet. Med. Assoc. 1994, 205, 472-476

3. Archer J.: Why do people love their pets? Evol. Hum. Behav. 1997, 18, 237-259.

4. Baruch Y., Holtom B. C.: Survey response rate levels and trends in organizational research. Human Relations. 2008, 61, 1139-1160.

5. Blackshaw J. K.: Developments in the study of human-animal relationships. Appl. Anim. Behav. Sci. 1996, 47, 1-6.

6. Concannon P. W.: Reproductive Cycles of the Domestic Bitch. Anim. Reprod. Sci. 2011, 124, 200-210.

7. Darbaz I., Ergene O., Sonmez G., Aslan S.: Ovarian tumor in a bitch: Diagnosis, surgery and recovery. Kafkas Univ. Vet. Fak. Derg. 2017, 23, 839-842.

8. Demirel M. A., Atalay Vural S., Vural R., Kutsal O., Günen Z., Küplülü S.: Clinical, bacteriological, and histopathological aspects of endotoxic pyometra in bitches. Kafkas Univ. Vet. Fak. Derg. 2018, 24, 663-671.

9. Dillman D. A.: Mail and internet surveys: The tailored designed method, $2^{\text {nd }}$ edn. New York, Wiley 2000.

10. Di Nardo A., Candeloro L., Budke C. M., Slater M. R.: Modeling the effect of sterilization rate on owned dog population size in central Italy. Prev. Vet. Med. 2007, 82, 308-313.

11. Downes M., Canty M. J., More S. J.: Demography of the pet dog and cat population on the island of Ireland and human factors influencing pet ownership. Pre. Vet. Med. 2009, 92, 140-149.
12.Feldman E. C., Nelson R. W.: Canine and Feline Endocrinology and Reproduction. $3^{\text {rd }}$ Edition. Elsevier Sciences Saunders Company, Missouri 2004.

13. Fielding W. J., Mather J.: Some observations on dog ownership in the West Indies: A case study from The Bahamas. Antrozoös. 2001, 14, 72-80.

14. Fielding W. J., Samuels D., Mather J.: Attitudes and actions of West Indian Dog owners towards neutering their animals: A gender issue? Anthrozoös. 2002, 15, 206-226.

15. Goethem B. V., Schaefers-Okkens A., Kirpensteijn J.: Making a rational choice between ovariectomy and ovariohysterectomy in the dog: A discussion of the benefits of either technique. Vet. Surg. 2006, 35, 136-143.

16. Günzel-Apel A. R., Zabel S., Bunck C. F., Dieleman S. J., Einspanier A., Hoppen H. O.: Concentrations of progesterone, prolactin and relaxin in the luteal phase and pregnancy in normal and short-cycling German Shepherd Dogs. Theriogenology 2006, 66, 1431-1435.

17. Howe L. M., Slater M. R., Boothe H. W., Hobson P., Holcom J. L., Spann A. C. Long-term outcome of gonadectomy performed at an early age or traditional age in dogs. JAVMA 2001, 218, 217-220.

18. Jackman J., Rowan A.: Free-roaming Dogs in Developing Countries: The Benefits of Capture, Neuter, and Return Programs, [in:] The State of the Animals. Salem DJ, Rowan AN, Eds.: Human Society Press. Washington D.C. 2007, p. 55-78.

19. Johnson C. A.: Pregnancy Management in the Bitch. Theriogenology 2008 $70,1412-1417$

20. Johnson C. A.: High-risk pregnancy and hypoluteoidism in the bitch Theriogenology 2008, 70, 1424-1430

21. Leney $J$ : Impact of companion animals on islands, issues and problems in their management: DOGS. Challenges of Animal Protection on Island Nations with Special Emphasis on Dogs and Cats, Miami, Fla 2002.

22. Marston L. C., Bennett P. C., Coleman G. J.: What happens to shelter dogs? Part 2. Comparing three Melbourne Welfare Shelters for nonhuman animals. J. Appl. Anim. Welf. Sci. 2005, 8, 25-45.

23. Menteş Gürler A., Melikoğlu B., Osmanağaoğlu Ş.: A historical evaluation of animal protection efforts of non-governmental organizations in Turkey. Kafkas Univ. Vet. Fak. Derg. 2011, 17, 901-908.

24. Murray J. K., Browne W. J., Roberts M. A., Whitmarsh A., Gruffydd-Jones $T$. $J$.: Number and ownership profiles of cats and dogs in the UK. Vet. Rec. 2010, 166, 163-168.

25. Müllersdorf M., Granstörm F., Sahlqvist L., Tillgren P.: Aspects of health, physical/leisure activities, work and socio-demographics associated with pet ownership in Sweden. Scand. J. Public Health. 2010, 38, 53-63.

26. Özen D., Böhning D., Gürcan İ. S.: Estimation of stray dog and cat populations in metropolitan Ankara, Turkey. Turk. J. Vet. Anim. Sci. 2016, 40, 7-12.

27. Poresky R. H., Daniels A. M.: Demographics of pet presence and attachment. Anthrozoös. 1998, 11.

28. Price J. H., Murnan J.: Research limitations and the necessity of reporting them. Am. J. Health Edu. 2004, 35, 66-67.

29. Root Kustritz M. V., Johnston S. D., Lieberman L. L.: Availability of training for prepuberal gonadectomy at North American Veterinary Colleges. JAVMA 2000, 216, 1566-1567.

30. Root Kustritz M. V.: Clinical Canine and Feline Reproduction Evidence-Based Answers. Willey-Blackwell Publication Iowa, USA 2010, p. 69.

31. Scarlett J. M., Salman M. D., New Jr J. G., Kass P. H.: Reasons for relinquishment of companion animals in U.S. Animal shelters: Selected health and personal issues. J. Appl. Anim. Welf. Sci. 1999, 2, 41-47.

32. Senger P. L.: Pathways to Pregnancy and Parturition, $2^{\text {nd }}$ ed, Current Conceptions, Inc. WA, USA 2003, p. 373-381.

33. Spain V. C., Scarlett J. M., Cully S. M.: When to neuter dogs and cats: A survey of New York State Veterinarian's practice and beliefs. J. Am. Anim. Hosp. Assoc. 2002, 38, 482-488.

34. Tuber D. S., Miller D. D., Caris K. A., Halter R., Linden F., Hennessy M.: Dogs in animal shelters: Problems, suggestions, and needed expertise. Physiol. Sci. 1999, 10, 379-386.

35. Westgarth C., Pinchbeck G. L., Bradshaw J. W. S., Dawson S., Gaskell R. M., Christley R. M.: Factors associated with dog ownership and contact with dogs in a UK community. BMC Veterinary Research 2007, 3, 5.

36. Vucinic M., Djordjevic M., Teodorovic R., Jankovic L., RadenkovicDamnjanovic B., Radisavljevic K.: Reasons for relinquishment of owned dogs in a municipal shelter in Belgrade. Acta Veterinaria (Beograd) 2019, 59, 309-317.

37. Zasloff R. L.: Measuring attachment to companion animals: a dog is not a cat is not a bird. Appl. Anim. Behav. Sci. 1996, 47, 43-48.

Corresponding author: Duygu BAKI ACAR, Assoc. Prof. Dr. Afyon Kocatepe University, Faculty of Veterinary Medicine, Department of Obstetrics and Gynaecology, TR-03200, Afyonkarahisar, Turkey; e-mail: dbakiacar@gmail.com 